\title{
POTENTIALITIES OF THE RELATIONSHIP BETWEEN TOURISM AND EDUCATION: Report of experience of the tourism awareness project in the city of São Bernardo Maranhão
}

\author{
Alanny Davila Silva Amadora \\ Karoliny Diniz Carvalhob
}

\begin{abstract}
The text presents a report of experience of a socio-educational action entitled Tourism Incentive Project (PROINTUR) developed by a group of students in the 6th period of the Bachelor in Tourism Course of the Federal University of Maranhão (UFMA), São Bernardo campus. The action was developed at the Deborah Correia Lima Teaching Center, and its main goal was to raise awareness among the school community regarding the importance of tourism as a socio-historical, spatial and cultural phenomenon, a factor for promoting economic growth, and an agent for social inclusion. The importance of tourism for community development is discussed, as well as tourism education actions, especially in the school context. This is followed by a presentation of the results achieved by the project. The work was based on bibliographic research, addressing the relationship between tourism and tourism education (Rabelo, 1998; Ribas, 2008; Fonseca Filho, 2007) and by pedagogical activities such as lectures, group dynamics and conversation circles with tourism and its production chain, tourist potential, and local development as the generating themes. The results of the intervention carried out show that the school community has knowledge about the importance of tourism; however, it has a restricted view of the tourist potential of the municipality of São Bernardo and the functions exercised by the bachelors degree in tourism as a transforming agent of the local reality.
\end{abstract}

\section{Keywords:}

Tourism

Local Development

Tourism Education

School Community

São Bernardo (MA) 


\section{INTRODUCTION}

Tourism has great educational potential in view of its socio-cultural, economic, environmental and political character. Some authors use the expression "tourist education" (Fonseca Filho, 2007) to address the interrelationships between education and tourism as a strategy aimed at recognizing the unique features of the places by the local residents, who may sometimes act as managers of this activity and, consequently, promote hospitality in tourist destinations. Through awareness raising and education projects for tourism, members of the local community will not only be able to act efficiently in the tourist activity, understanding its role as an agent of socioeconomic development, but will have a critical view of the reality and the place where they live

In view of this perception, our focus of interest is the municipality of São Bernardo, Maranhão, in the region known as Baixo Parnaíba Maranhense (Figure 1).

Figure 1 - Location of São Bernardo, Maranhão, Brazil

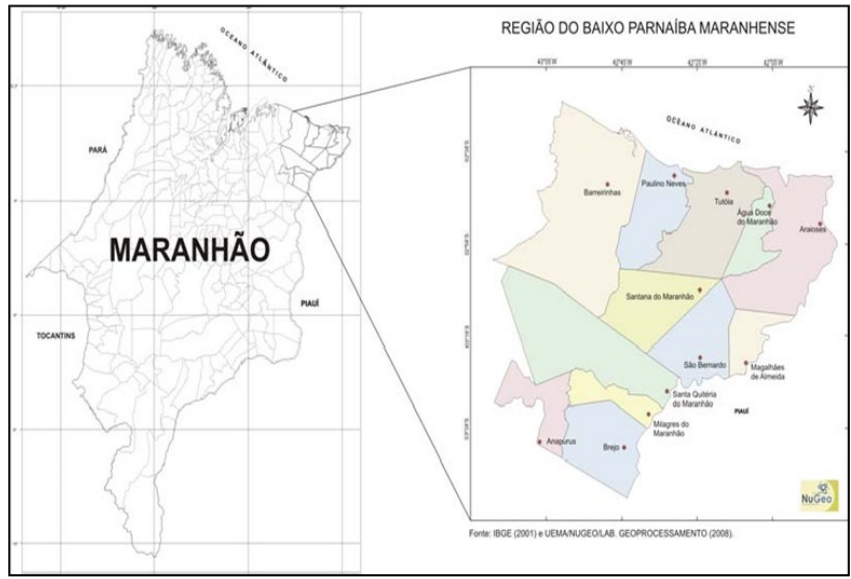

Source: IBGE (2000).

This region is strategically located between two tourism districts of Maranhão, or "Polos" as they are known in Portuguese: the Polo Munin and the Polo Lençóis Maranhenses, and is situated on a route that must be taken to reach several other cities, such as Parnaíba (PI) and Fortaleza (CE). It is a region with good tourist potential, particularly due to its religious festivities and natural and ecological attractions. The existence of these attractions, and of a predominantly rural population, creates opportunities for community-based ecological, rural, leisure and tourism routes.

Despite this, there is no significant tourism activity in the daily life of the place, bringing significant economic changes or impacts on basic infrastructure and services. There are a few indications of tourism development, but the local community is still not aware of the full tourism potential of the municipality and the job opportunities that the tourism and hospitality sectors can offer.

In view of this reality, the Tourism Incentive Project (Projeto de Incentivo ao Turismo - PROINTUR), was developed by students in the 6th period of the Bachelor of Tourism Course at the Universidade Federal do Maranhão (UFMA), São Bernardo campus, with the aims of socializing knowledge about tourism among the local community and investigating various aspects of tourism which, besides being a factor of local development, is also a major economic factor in the locality, generating employment and income, boosting the economy, and bringing local development for the community, with mutual solidarity and sustainability.

For the preparation of this work, a literature review was conducted, focusing on authors who address the relationship between tourism and tourism education (Rabelo,1998; Ribas, 2002; Fonseca Filho, 2007). The report of experience that follows is divided into sections. Initially, the issue that led to the emergence of the project is addressed, highlighting the importance of projects to raise awareness of tourism, and provide education for local communities on the subject. Next, the methodological procedures and socio-educational activities carried out in the school environment are presented. Finally, the main results achieved within the scope of university intervention are discussed.

This work aims to establish a dialogue between education and tourism with a view to enhancing the material and symbolic heritage of the municipality of São Bernardo, as well as its tourist use from a perspective of local development.

This work aims to establish a dialogue between education and tourism a view to enhancing the material and symbolic heritage of the municipality of São Bernardo, as well as its tourist use from a perspective of local development.

\section{PROBLEM AND RELEVANCE}

Tourism and education are closely related, be it formally or non-formally. As stated by Peccattielo (2005, p.10), the aim of tourism education is to expand the students' view, as agents that can transform the reality, "capable of modifying, developing and enriching the instruments of action and interpretation in the social sphere". Given the interdisciplinary nature of tourism, it can be taught in schools, either in an inter-curricular way, or as a permanent discipline in the curricula of certain periods, or through pedagogical tourism associated with educational visits and school trips.

This perspective has been addressed at national level by Portuguez (2001), Ribas (2008), Peccatiello (2005), Fonseca Filho (2007), among others. Dias (2006, p. 61) 
notes that "the school activities must always be in line with the reality of the community it serves. The school must approach the world of work, introducing students to different professions and clarifying their characteristics".

It is worth mentioning that most scientific production is focused on higher or professional education, with few works that focus on primary and secondary education. The educational potential of tourism is conceptualized by Fonseca Filho (2007, p.30) as Tourism Education $(\mathrm{ET})$, the purpose of which is to: "[...] Disseminate knowledge about tourism in society, through actions aimed at education, be they formal, non-formal or informal. This practice is more present in tourist cities or places with tourist potential, and the public served is composed of citizens and tourists who visit the location".

The use of tourism as a pedagogical tool can assist in the education of students in basic education (early childhood, elementary and high school) enabling them to learn, contextualize and assimilate the curricular content, to assist the teaching-learning process. Rebelo (1999, p.23) also emphasizes that the relationship between formal education and tourism "has the possibility of forming tourist consciousnesses, manpower for tourist services and specialists, through the school", that is, it allows residents to take ownership of their cultural assets and natural resources in a way that values and preserves them.

Ribas (2002, p.15) corroborates this idea, pointing out that "educating the community, starting with children and young people, is one of the means to promote tourism in the community that receives tourists", as it allows young students feel an integral part of tourism development proposals and act as multiplier agents, exercising the role of transforming their realities, through local initiatives involving tourism.

It is understood that education by and for tourism involves raising the awareness of tourism actors, aiming to minimize the negative impacts and maximize the positive impacts generated by tourism in the host communities (university extension course, tourism departments, employment and income, nongovernmental organizations, etc.) as well as training and qualification of the workforce for the tourism sector, through technical and higher education courses, a subject addressed by several national authors (Rebelo, 1998; Silva, 2002; Fonseca Filho, 2007).

Linking tourism with education can be a strategic action for destinations seeking to develop their economies through this activity. It allows students to understand the meaning of tourism, the role played by the tourism sectors in promoting municipal economic growth and development, the areas in which tourism professionals operate, the need to understand and value history, culture, heritage, preserve the environment, and other issues that are important to avoid the nega- tive impacts caused by tourism.

Thus, the involvement and participation of the local community in tourism are necessary conditions for this activity to develop, based on local values, and it can add value to other existing economic sectors, stimulating local-based initiatives that can contribute to promoting social development and improving the quality of life.

\section{METHODOLOGY}

The location chosen for the development of the project was the Centro de Ensino Deborah Correia Lima (Figure 2), located at Travessa Alexandre Mendes, 03, Centro, São Bernardo, Maranhão. It is a state public school, approved on 12th March, 2009 and recognized by Resolution No. 253/2009 CEE/MA (State Education Council of Maranhão) and the MEC (Brazilian Ministry of Education).

\section{Figure 2 - Deborah Correia Lima Teaching Center}

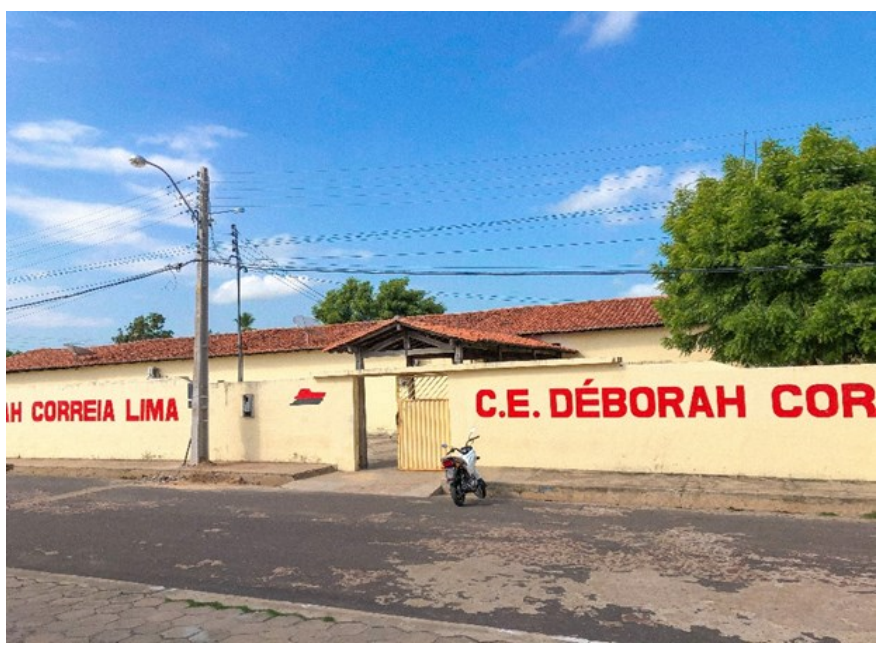

Source: Carvalho (2019).

Based on the theoretical construction of the proposed intervention, contacts were made with the school management to define the class and period in which the activities of the project would be carried out. It was decided on the 3rd year class, with 33 students, due to the fact that this group is almost finishing the cycle of high school and would be better able to envision the performance in areas related to tourism and hospitality.

First, the aims of the project were explained to the students. Then, a conversation was held with the students, using objects related to the universe of tourism. There was a discussion about tourism and its relations and, within this dynamic, the students were asked to take from the suitcase an object that most caught their attention, as a way of focusing on each 
element of the tourism production chain and the essential elements of a tourist trip - attractions, travel agencies, accommodation, means of transport, tour guide, leisure equipment, events, destination marketing.

In addition to attracting students 'attention interactively, in order to stimulate a critical view of tourism and the tourist potential of the Baixo Parnaíba Maranhense region, the activities aimed to allow an understanding of the role played by them in promoting local socioeconomic development (Figure 3).

Figure 3 - Activities of the PROINTUR project

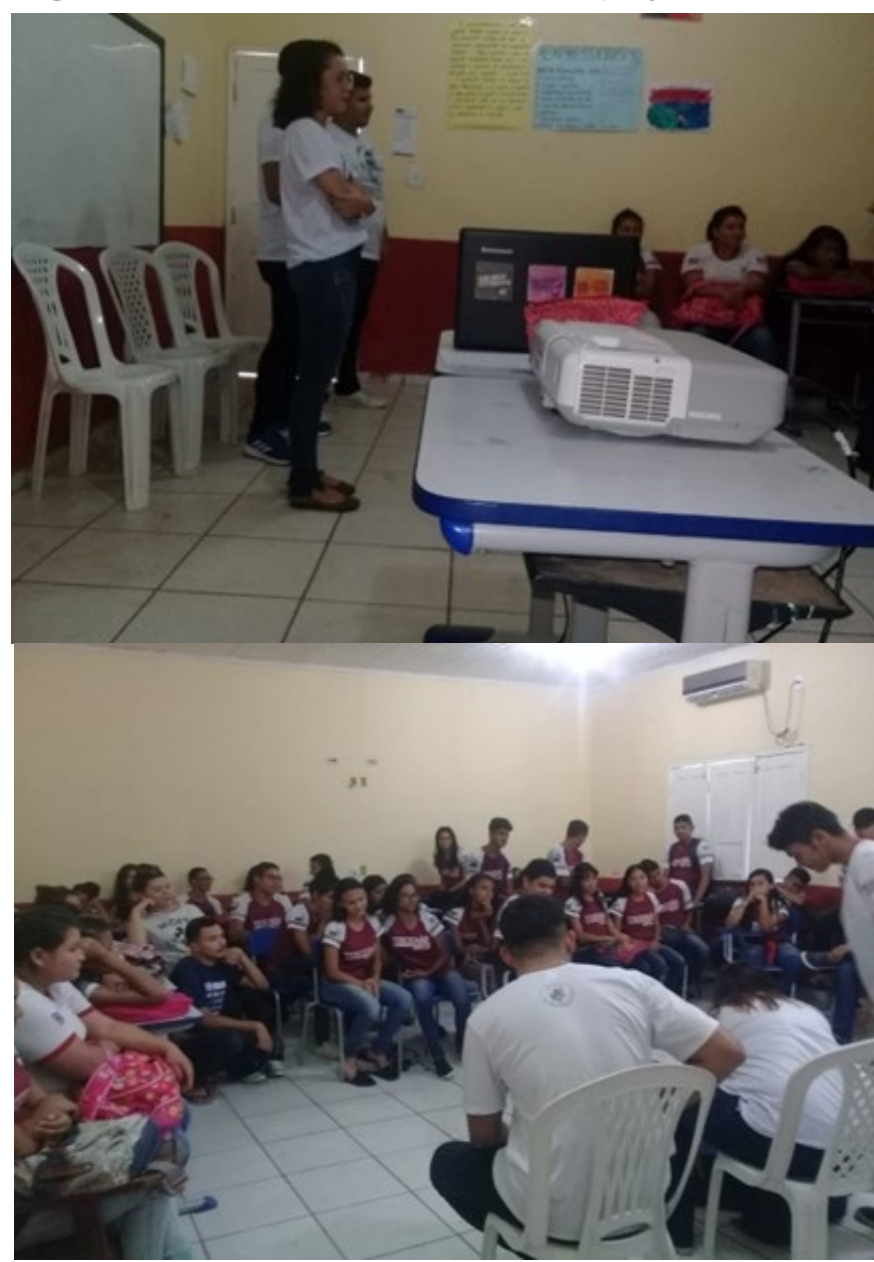

Source: Project collection (2019).

In the second stage, based on the previous dynamics, the profile of the tourism expert was presented to the students, raising discussions such as "What is a tourist specialist?", "The difference between tourismologist and tourist guide"," and "The areas of activity of tourism". The contents were approached in a dynamic and informal way, encouraging interaction and allowing all the students to express their opinions and views on the subject. In the third stage, the class was dedicated to a discussion about the tourism course in the region, how the course works in practice and theory, and how im- portant it is to have student representation within the course (Figure 4).

Figure 4 - Lecture with a representative from the course

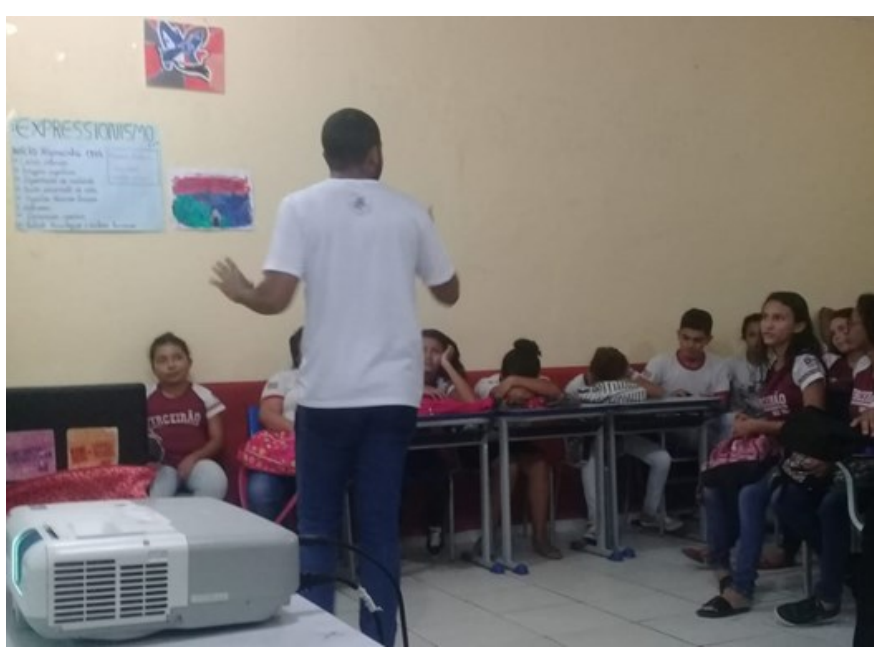

Source: Carvalho (2019).

In the fourth stage, a group dynamic called "country compliance" was developed. In this activity, some different forms of greetings of other countries were presented, followed by a discussion of the importance of valuing cultural diversity, through a playful and creative exercise, and its relevance to the theme of travel and tourism.

Next, the students showed photos of field trips they had carried out, explaining the importance of interdisciplinarity for understanding tourism, and the need to articulate theory and practice in university education. The session ended with a coffee break.

\section{RESULTS}

The project took place on June 4, 2019, at the Deborah Correia Lima state school, and involved a class of 33 high school students. An initial aspect to be highlighted was the receptivity to the project among the management and teachers of the school. Through conversations with the school Coordinator, we learned that the school always seeks to develop projects that involve the study of local reality in different disciplines. For example, the partnership between the school coordination and the Universidade Federal do Maranhão (UFMA) could be seen in the significant number of pedagogical projects that are developed throughout the school term.

As regards the students involved in the PROINTUR project, it was noticed that some of the students had a restricted view of the real meaning of tourism and its importance for the development of the Baixo Parnaíba 
Maranhense. Some of them enquired about the areas of activity of the Bachelor in Tourism. The participants showed a good understanding of the tourist potential of the municipality of São Bernardo and neighboring areas, pointing out some attractions that could be used as elements or factors of tourist attraction, such as the church, religious festivals, and villages.

But it was found that despite being able to point out some of the local tourist attractions, the young people did not have a sense of affection towards the historicalcultural and environmental heritage, which in the long term, can compromise actions in favor of municipal tourism. The project monitors highlighted the need to raise awareness of the city and its tourist potential, as tourists seek attractions that are different from their daily lives.

In this context, the municipality of São Bernardo can develop offers of rural and ecological tourism, as well as community-based tourism. "[...] in tourism there is increasing talk about experience, experiencing and living together, because these are the great mobilizers of strangeness (Gastal \& Moesch, 2007, p. 12).

The students also pointed out some environmental problems experienced by the municipality, such as the issue of garbage. Tourism awareness initiatives should also include environmental and heritage education actions so that students, young people and the community in general can realize the importance of the historical and natural heritage, as symbols of the community's culture, history and identity.

These results confirm the need to develop tourism awareness and awareness projects and heritage education for the community. Tourism planning in any city must be accompanied by strategic actions to raise the community's awareness so that it can act in the tourism sectors and enhance the value of urban or rural spaces:

[...] Through awareness, tourism education will influence people's culture, provide better contact between the tourist and the visited community, form subjects who can later work with tourism, and enable the creation and implementation of tourism policies aimed at educating the population (Silva \& Maracajá, 2012, pp.277).

Tourism is able to boosting economies, strengthen identities, and promoting local territorial development, helping to reverse economic imbalances, However, it is necessary for the community to have a broad and critical view of this phenomenon, working closely with official bodies, councils and forums and effectively participating in planning and decision-making in the tourism sector. Rebelo (1999, p. 97) highlights some of the long -term benefits that education linked to tourism can bring for a location:
The positive effects of tourism education are all those that are supposed to be positive consequences of having an educated community for the activity in the tourist nucleus. They derive, for example, from the local pedagogical possibilities of training specialists, training manpower, raising community awareness, intervening in changing needs and being an example for imitating or assimilating appropriate behaviors, meaning that education has what it takes to contribute to the tourist development of Brazilian municipalities with tourist potential.

Based on the actions carried out, PROINTUR achieved the following results: a) raising awareness among the school community about the importance of tourism; b) strengthening the relationship between the UFMA and the local community; c) improving recognition of the tourist potential of Baixo Parnaíba Maranhense; d) developing practical skills in tourism students and e) encouraging interest in participating in teaching, research and extension projects among students of the Bachelor in Tourism.

The PROINTUR is a pioneering initiative that brings together tourism and formal education, raising awareness among the local actors about the importance of tourism as a social phenomenon and a business-generating activity for the city. Tourism awareness actions seek, above all, to alert the school community to the importance of urban and rural spaces, from a perspective of integrated development and the local community. This initiative, due to its low cost and high potential, can be replicated in other locations seeking to develop tourist activity, showing managers the need to raise community awareness of the importance of its historical and cultural heritage. It is understood that articulation between tourism and education is promising as allows articulation between the different areas of knowledge, encouraging the residents to value the city from the perspective of citizenship and social inclusion.

\section{PRACTICAL IMPLICATIONS AND CONCLUSIONS}

The proposed dialogue between the Bachelor of Tourism course at Universidade Federal do Maranhão - UFMA, São Bernardo campus, through PROINTUR and the student community, arose out of a need to socialize information and knowledge of the tourism phenomenon, and how it could be developed in the city, given that the municipality of São Bernardo is situated on a strategic route between two tourist centers of Maranhão, which demonstrates its potential for tourism.

This choice was made due to a perceived need for a greater partnership between the university and community, and the great potential of São Bernardo for 
tourism. However, it was observed that the local community is not fully aware of the scope of tourism and the benefits and positive impacts that this activity can bring, whether in the preservation of environmental and cultural heritage, or in the diversification of economic sectors thanks to its multiplier effect, as well as its potential to involve the local community in mutual enterprises and territorial-based and local initiatives.

The results of the intervention carried out show that the school community in the municipality of São Bernardo has some knowledge about the importance of tourism, but that this knowledge is limited when it comes to the opportunities that local tourism can bring, and the functions exercised by the graduate of the Bachelor in Tourism, as an agent for transforming the local reality.

Therefore, the need to promote a closer relationship between the teaching, research and extension projects of the UFMA alongside the local community is highlighted, in order to produce and socialize knowledge about the tourist phenomenon, the economic, social, cultural and environmental impacts, and the areas in which bachelors or professionals in tourism work. Through this initiative, it is possible, in the long term, to achieve a tourist destination in which the local community is aware of the potential, and educated in the area of tourism and citizenship.

\section{REFERENCES}

Dias, G. F. (2006). Interdisciplinary environmental education activities: innovative environmental education practices. 2. ed. São Paulo: Gaia.

Fonseca Filho, A. S. (2007). Education and Tourism: Reflections for Development of a Tourism Education. Brazilian Journal of Tourism Research, 1(1), 5-33.

Gastal, S.; Moesch, M. (2007). Tourism, Public Policies and Citizenship. São Paulo: Aleph.

Peccatiello, A. F. O. (2005). Pedagogical tourism as a teaching-learning strategy from the perspective of the National Curriculum Parameters - 3rd and 4th cycles of elementary education. Global Tourism Magazine. São Paulo.

Portuguez, A. P. (2001). Consumption and space: tourism, leisure and other topics. São Paulo: Roca.

Rebelo, S. M. (1998). Municipal Plan for Tourism Education / PMET: a model for Brazilian municipalities with tourism potential. Tourism Vision and Action Magazine. Balneário Camboriú (SC), 1(2), 89-106.

Ribas, M. H. (2008). Education for tourism. A view from the Professor, 5(1), 9-20. Available at: https:// revistas2.uepg.br//index.php/olhardeprofessor/ article/view/1372.
Silva, G. B.: Maracajá K. F. (2012). Environmental education and tourism education in elementary schoo at the Quintino Bocaiúva State School Palmira Barbosa Municipal School in Santa Cruz (RN). Virtual Tourism. Rio de Janeiro, 12 (3), 272-286. 